\title{
Studies of Postcolonial Theory and Postcolonial Translation Theory
}

\author{
Xue-min HENG \\ Xiamen University Tan Kah Kee College \\ Xiamen, Fujian, China
}

\begin{abstract}
The 1980s witnessed the collapse of the traditional colonial system and the emergence of a new age, the cultural colonization era, namely the post-colonialism era. Given such a context, the definition of translation should be renovated with new understanding and interpretation, so that translation can be better served as a tool of cultural information communication. And translatology is a young and immature discipline situated on the periphery of academia, which is nourished during the theoretical construction. As for translation studies, theories of post-colonialism provide translation studies with a new perspective that helps the effective integration of ideas and methods in a harmonious and complementary manner, hence promoting the further development of this area.
\end{abstract}

Keywords-Postcolonial Theory; Post-colonial Translation Theory; Translation Strategies

\section{INTRODUCTION}

Post-colonialism is one of the latest currents of thought that abruptly flourished at the end of 1980s and is gradually taking the center stage in the cultural and literary circles of the western world. It is also one of the most influential and rapidly developing academic schools in the late 20th century. Researches of post-colonialism, as a critical discourse, took lead in extending to the fact and results of the West-to-East cultural colonization as well as shifting the focus from the textual form to the cultural and political criticism, showing a new academic tendency [1]. Theories of post-colonialism emphasize analysis on the cultural invasion of imperialism, relation between suzerain and colony, cultural character and political intervention of third-world intellectual elites, and wording of the racial, cultural or historical "others" with the purposes to reveal the limitation of the Western metaphysical discourses, to explore the interplay between colonialism and the Western cultures, and to inspect how such an interplay is expressed. Given the massiveness, complexity and ongoing evolution of the theoretical system of post-colonialism, usually it is only viable to generalize its main features. Postcolonialist Translation studies examine the translation practices under different historical conditions from the perspective of post-colonialism, affirm the power differentials among cultures, and highlight the power struggles and operations between two cultures as implied in each translation work. They intend to reinforce the understanding towards translation practices through the elaborations of the inequality and asymmetry among varied nations, cultures, races and languages. The dissertation attempts to provide an in-depth analysis on the impacts of post-colonialist studies on the entire system of translation theories by the review of post-colonialist translation studies in recent years. While recognizing the theoretical value of such studies, we've also pointed out their limitations and carried out relevant examination to further grasp post-colonialist translation studies. Post-colonialism has gathered attention from both the culture researchers and the area of translation study. Post-colonialist translation studies investigate the translation practices under different historical conditions from the perspective of post-colonialism, emphasize unearthing from translations works the power struggles and operations between two cultures, and hence raise fundamental challenges towards the theoretical assumption in respect to the cultural and language equality in traditional translation theories. Discussion around post-colonialist translation theories centers on the selection of translation strategy.

\section{STUDIES OF POST-COLONIALISM AND POST- COLONIALIST TRANSLATION}

Post-colonialism refers to a reality of cultures or cultural researches that originated since the termination of colonialism and relevant experiences. Such a reality features the focus on a series of language, cultural, legal, educational, political and other problems that are related to group identity, particularly the emphasis laid on the discrepancy between these problems of different categories, and the skepticism to the simplified solutions taken against complex problems based on absolute purification [2]. Explorations about post-colonialism theories generally commence with the classical piece of Edward Said. In this sense, it is the academic thoughts produced in the first world that constitute the core or post-colonialism theories and enable the relocation of global post-colonialism theories from "background" to "foreground". Different from any modern Western schools, remarkable theoreticians in the area of postcolonialism almost to a man share a dual identity; they are both the established professor in a Western college and the descendant of a third-world country. Post-colonialism theories not only inherit logical continuation of Western ideological traditions but also soar above the simple development of Western thoughts; such a particularity provides a new departure for global thinking.

With regard to the historical retrospect of academic pedigree, post-colonialism theories derived from literary and cultural researches, and gradually permeated across the rest of humanities and social sciences. The idea of post-colonialism is by its nature a temporal concept referring to the new historic period that came into being after the disintegration of colonialism. It surpasses colonialism and has a touch on the 
neocolonialism. In the era of globalization, even the imbalance and inequality between powerful countries and vulnerable countries, which are not colonially connected, have entered the scope of post-colonialist studies. Post-colonialism theories dispel and disapprove the cultural hegemony of imperialism, while post-colonialist translation theories advocate for the post-structuralism ideas that revolve around deconstructionism in the field of translation studies. The centrality of text, author and translator in the course of translation has been removed; more attention is paid to the ideology, culture and politics. Born in the 1980s, post-colonialist translation studies provide a new perspective of translation study based on the deconstructionism, hermeneutics, polysystem theory, descriptivism, teleology and new historicism. As illustrated above, the theories "investigate the translation practices under different historical conditions from the perspective of postcolonialism, emphasize unearthing from translations works the power struggles and operations between two cultures, as well as highlight the power differentials and ever absence of the truly equal dialogue between cultures." The political and economic imparity in the context of post-colonialism result in the power differentials between dominant and dominated cultures and hinder translation practices from leading to the expected equal dialogues and information conversions. More precisely, post-colonialist translation is a tool for third-world countries to "liberate their own national cultures from the shackles of former suzerains, improve the marginal status of local cultures, reshape the cultural identity, reorient the cultural relationship between the West and East, and promote the equal participation in the cultural communication and exchange." It is based on such power differentials that postcolonialist translation studies investigate the translation strategies that translators of different value orientations have adopted, consciously and unconsciously.

Compared to traditional translation studies, those regarding the post-colonialism are more concerned with the external restrictions upon the production of translation. They tend to demonstrate the history-right and history-politics correlations to rewrite the history. By investing the translation practices under different historical conditions from the perspective of post-colonialism, Post-colonialist translation studies uphold the existence of power differentials between cultures and emphasize the power struggles and operations between two cultures as implied in translations works. Based on the theory of power differentials, post-colonialist translation studies apply the descriptive manner to observe, analyze and explain the conscious and unconscious value orientation and strategy selection made by translators in the context of power differentials. The practices of translation contribute to the power asymmetry in the colonial relations. The descriptive elaboration of the connection between the translation work and historical conditions reveals the specific era and power contrast under which each was produced and proves the translation violence. As for theorists of post-colonialist translation, translation is the kind of practice that shapes the power inequality in colonial relations. Different from traditional translation theories, post-colonialist translation theories focus on the external constraints upon the translation generation and the disruptive impacts of the produced translation on the target culture. Post-colonialist translation theories build on the ideology of power differentials to observe, study and explain the value orientation and strategy determination made consciously or unconsciously by the translators in the context of power differentials in descriptive languages.

\section{SElEction of Translation StRATEgy Under Post- COLONIALISM PERSPECTIVE}

Post-colonialist translation theories feature the linkage between translation and politics as well as the exploration of how translators from a disadvantaged nation or language choose the translation strategy due to the influences of ideology, power and other factors. The translation strategy alienation or domestication - in post-colonialist translation studies is often related to the progress of "colonization" and "decolonization". The so-called "de-colonization" refers to "the removal of negative influences from colonization, in particular the gradual termination of collective inferiority under the colonization," namely the dynamic process of small and weak nations getting rid of colonial rule and gaining independence. Many researchers of post-colonialism believe that, in order to repel the invasion of advantageous cultures and cast off the restrictions of spiritual colonization, "the 'alienation' of translated texts produced for Anglo American readers carry the strategic de-colonization significance of overthrowing the colonial ideology." Advocated by Lawrence Venuti, the Resistance Translation is an alienation strategy that aims to liberate readers and translators from the muzzles of powerful cultures in the course of reading and composition. Such an idea insists that "translation should display the language and cultural discrepancies and accommodate the realization and investigation of these discrepancies."[3]

In the meanwhile, theorists of post-colonialist translation believe that translation is a cultural and political action, and the domesticated translations propagate Anglo American culture and ideology, hence demonstrating the inequality of cultural communication. The inconformity with conventional expression that alienated translation features in its unidiomatic, incoherent and opaque wording is the result of a deliberate effort that retains the "alien" part of the foreign texts with the intent to run counter to the cultural norms of the target language. Post-colonialism theorists hold that translation is a weapon of imperialistic expansion. The arbitrary emendations and distortions that imperialists impose on the works in their colonies lead to domesticated translations untrue to the originals. Translation in the circumstance of post-colonialism serves as a tool for imperialist states to exercise mental control over the colonized people. With respect to the themes of translation works, hegemonic cultures generally prefer sagas, thrillers and similar popular writings, which exert pleasure without triggering criticism, in determining the texts to be translated for the third-world countries. Post-colonialist translation theories thoroughly renew the meanings of alienation and domestication, the two translation strategies, by paying heightened interest to the power relation between two cultures (involved in each translation practice) and their ideologies. In post-colonialist translation studies, the choice of translation strategy between alienation and domestication is often relevant to the progress of colonization and 
decolonization. De-colonization refers to "the gradual termination of collective inferiority under the colonization," namely the dynamic process of small and weak nations getting rid of colonial rule and gaining independence. As a discursive practice, domesticated translation constructs the power irreciprocity in the colonial relation; all the disadvantageous cultures have to suffer the manipulation of the advantageous Anglo American culture. Translation domestication plays the role of accomplice when the colonizers are implementing cultural colonization and strengthening colonist ideologies, namely it not only facilitates for colonizers the dissemination of discursive powers and the implementation of cultural embezzlement, but also continuously reinforces the selfidentification among the colonized nations.

In the post-colonialist context, theorists of postcolonialism advocate for the translation strategy of alienation in order for translation to change the long-lasting status of subordinate slavishness and release its true power. It is the resistance from the Oriental dominated cultures against the Western dominant cultures. Counter-hegemonic intellectuals, represented by Venuti, call on US translators to adopt the alienation strategy so that foreign texts carrying numerous lingual, cultural and value differences can be brought in for American readers to repel and correct the hegemonic ideology fostered by the domestication practices. Venuti has proposed the Resistance Translation - i.e. the alienation strategy - that enables readers who speak the target language and translators to be extricated from the limitations of advantageous cultures during the reading and composition. When the culture of European suzerain occupies the central position, the colonizer as well as its language and culture are regarded as the dominant "originals" while the colony as well as its language and culture are deemed as the subordinating and subsidiary "copies". In the context of post-colonialism, the relation between the colonizer and colony is often manifested as the relation between the first-world country and third-world country. Translation plays a pivot role in the colonization by aiding the spiritual control that imperialist states exercise on the colonies. In the course of colonization, the colony is deprived of the freedom of equal cultural communication due to the control of the suzerain over its culture. On the other hand, the tremendous profits that hegemonic cultures earn from the translation and sales of their popular literature in the third-world countries during the post-colonialist period are not invested in the introduction and translation of the texts coming from these disadvantaged nations. For example, the Anglo American market of translation works sees both the largest output and the smallest input across the world. Furthermore, the Anglo Americans always keep in mind that translation is a subversive act in the political and cultural sense; the domestication principle is applied as extensively as possible in the limited input, from the selection of works to be translated to the determination of translation strategy. It is because that such a principle encourages the translation of foreign writings into the dominant colonial power's own language to eliminate cultural differences. This indicates that texts from disadvantageous cultures, after the meticulous screening of hegemonic ideologies, serve to reinforce the colonial consciousness of readers of the hegemonic cultures.
In order to realize the spiritual control over the colonies, and later the third-world countries, hegemonic cultures prefer sagas, thrillers and similar literature when choosing for these nations the texts to be translated. Such popular writings excite pleasure without inviting criticism. The Anglo American values introduced by these translation works foster a group of westernized readers who become ignorant of their local cultures. They are involuntarily triggered into the trap of imperialist ideology in a gradual and subtle manner after their minds are "translated". As for the colonial expansion and cultural invasion of imperialism, translation philosophy is not only a matter of language or translation technique, but ultimately a political and cultural strategy of disruptive energy The tremendous profits that hegemonic cultures earn from the translation and sales of their popular literature in the thirdworld countries during the post-colonialist period are not invested in the introduction and translation of the texts coming from these disadvantaged nations. For example, the Anglo American market of translation works sees both the largest output and the smallest input across the world. Furthermore, the Anglo Americans always keep in mind that translation is a subversive act in the political and cultural sense; the domestication principle is applied as extensive as possible in the limited input, from the selection of works to be translated to the determination of translation strategy. It is because that such a principle encourages the translation of foreign writings into the dominant colonial power's own language to eliminate cultural differences. The expression of domesticated translation shows a transparent and fluent style without any trace of translating act or translator. However, the domestication process that adjusts the translated texts according to the lingual, cultural and literary norms of the target language disqualifies these works as faithful translation. The guiding principle that highlights above all the acceptance of readers, the conformity to the preference of audience, and the cultural, political and ideological needs of recipients have excluded the faithfulness from the primary criteria of translation long ago. Under the domestication strategy, emendations and alternations out of utilitarian purpose are applied to the translation of texts to be exported to the European and US market. Translation becomes a significant showcase of the power asymmetry among different nations, races and languages. As a challenge to the dominant status and the long-deemed sole effectiveness of domestication strategy, Venuti has proposed the Resistance Translation - i.e. alienation - to enable the emancipation of readers who speak the target languages and the translators from the constraints of advantageous cultures in reading and composition.

Translators of post-colonialism regard translation as a political act. They disapprove the application of domestication strategy to the Oriental literature by the Western colonizers and vigorously promote the alienation practices in the translation of foreign writings. Alienation requires the deliberate effort to retain the "alien" part of the foreign text, breach or attack the cultural norms of the target language, adopt the unidiomatic, incoherent and opaque wording that disobeys the conventional expression, and complement/reveal the silences, blanks and absences in the original text. In the post-colonialist context, theorists of post-colonialism advocate for the translation strategy of alienation in order for translation 
to change the long-lasting status of subordinate slavishness and release its true power. Each culture, if with no plan of seclusion, should engage in communication. And to communicate, it must embrace the hybridization. The continuous hybridization to an appropriate degree helps enhance the immunity and reduce the exclusiveness for the cultural organism. The only way to avoid the adversity of colonization and to fundamentally resist cultural invasion is to keep elevating the cultural status. Hybridization refers to the blending process of various races, populations, ideologies, cultures and languages. The idea of hybridization is introduced into the area of post-colonialism by Bhabha, the postcolonialism researcher. Bhabha argues against the rigid binary opposition between alienation and domestication in the traditional translation theories by placing a "third space" between the two poles. He has an apparently different understanding towards the globalization from that of the Eurocentrists and West-centrists. It is his belief that, on the one hand, hegemonic cultures are influencing weaker cultures with their values and ideologies in pace with the globalization blurring the differences between national cultures; however, on the other hand, the disadvantageous cultures are unwilling to submit, as is shown in their ceaseless efforts to combat against such influences in a silent and invisible manner. Such efforts of resistance and revolt are mainly manifested in the cultural anti-permeation, proving the unstoppable tendency of cultural diversity. It is without doubt that cultural gaps have become more prominent in the era of postmodern space and post-colonialism. Even the purest white supremacy and colonial discourse are now attached with "hybridity" and "ambiguity" by post-colonialists. It is the interspaces created by such a hybridization that has led to something new and the neutral "third space", which provides the foundation for the experiments of cultural translation.

Post-colonialist translation theories underline the hybridization of languages, cultures and values as reflected in the translation texts and emphasize the historical operations of power discourses behind such a hybridization as well as its profound influences on specific culture and ideology. Hybridization to some extent is admittedly inevitable in the language of translated foreign texts that are introduced in certain local culture, whether the adopted strategy is alienation or domestication. The only difference between alienation and domestication is the degree of hybridization. Post-colonialist Translation theories underline the hybridization of languages, cultures and values as reflected in the translation texts and emphasize the historical operations of power discourses behind such a hybridization as well as its profound influences on specific culture and ideology. Hybridization to some extent is admittedly inevitable in the language of translated foreign texts that are introduced in certain local culture, whether the adopted strategy is alienation or domestication. The only difference between alienation and domestication is the degree of hybridization. Even the least degree of hybridization facilitates the introduction of foreign language, culture and value into the target culture. Even the highest degree of hybridization, to the contrary, can hardly lead to the outright destruction of the national identity of the target culture.

\section{VALUES AND LIMITATIONS OF POST-COLONIALIST TRANSLATION THEORIES}

Previous translation theories are for the most part based on language analysis, while post-colonialist translation theories manage to overstep unitary lingual researches and constitute a new model of translation criticism by the application of academic outcomes in politics, sociology, culturology, anthropology, literature, philosophy, psychological analysis and other areas into the studies on texts and behaviors from various cultures. Translation studies of linguistics examine translations in static environments. By contrast, the methodology of post-colonialist translation studies requires the on-the-spot investigation of translation practices in the same manner as cultural archaeology and discovers one of the important factors that affect translations practices: the power differentials in power discourses. Post-colonialist translation studies make the first breakthrough by unearthing the political and power issues in translation practices, which have been long existent yet covered, and further highlight the influences of power, ideology and other factors on translation researches. In the meanwhile, they provide a new perspective of translation criticism that pays attention to not only the texts but also the relation between dominant and dominated cultures outside the texts. It is hence recognized that disadvantageous cultures and languages have been suffering marginalization and lack of objective understanding from external world for a long time, due to the reality that hegemonic countries are carrying out cultural invasions through translation practices that arbitrarily falsify disadvantageous cultures and languages to ensure the conformity with the advantageous cultures and languages. Firstly, the investigation of translation activities in the broader framework of international politics and cultures and the emphasis on the right relations and historical contexts embodied in translation texts in the post-colonialist translation studies make them highly meaningful communication between translation researchers and other branches of humanities and social sciences, in addition to endowing the discipline of translation study with theoretical depth and development prospect. Secondly, the emergence of post-colonialist translation theories is in a large part inspired by deconstructive translation. The theories apply ideas of deconstructive translation to the elaborations on translation from the perspective of post-colonialism, which marks a new upsurge of translation studies. Post-colonialist translation theories believe that translation is a tool of imperialist expansion.

The imperialist control over colonies is not only physical but also spiritual. In the course of conquest, translation plays a vital role as the tool for imperialists to intensify spiritual control on the colonized people. During the colonization, the control of suzerain impedes the culture of colony from the equal communication with the colonizing culture. Colonizers "legitimize their rules and consolidate the hegemonies through translated texts that record their impression of the colonized people, namely the national or racial archetype."[4] Postcolonialist translation theories provide theoretical weapons for the third-world countries to get rid of the cultural colonization. Post-colonialism theories "not only form the cultural strategy that guides the third-world countries to establish 'dialogue' with first-world countries, but also enable the marginalized 
cultures to rediscover the prospects of themselves and their national culture."[5] The advocacy of post-colonialist translation theories for the equality between national cultures and languages poses an unprecedented challenge to the system of the Western translation theories that dominate in the circle of translation theories and urges Westerners to discard the long-lasting prejudices towards the Orient. They liberate translation studies from the mode adopted in the dominant Western cultures, support third-world countries to recognize their position in the global translation system, to advance the outstanding local traditional culture, and to reinforce the national pride and confidence, as well as assist the development of a balanced and diversified system of translation theories.

As great as the achievements that post-colonialist translation studies have made in recent years, there remains much to ponder in the post-colonialist translation theories. As an academic area in its infancy, post-colonialist translation theories inevitably show multiple problems despite the various inspirations and theoretical references they've provided. The first problem is that such theories bear no universal relevance given the varied degree of cultural invasions that different third-world countries are suffering. Secondly, post-colonialist translation theories merely underline the Oriental resistance against the Western cultural hegemonies from the postcolonialist perspective, yet evade or neglect the origin of the cultural differences between the West and the East. Such differences result from the joint functioning of various factors, hence translation studies should not emphasize confrontation but ignore communication. It is a problem of urgent demands for reflection and resolution by the scholars and citizens of the colonized countries in the post-colonial era. In the third-world countries, the excessive stress that post-colonialist translation theories lay on the power differentials can easily arouse the hostile public attitude towards the Western cultures, trigger the parochial nationalistic sentiments and backlash against Western cultures, and further lead to cultural conservatism and narcissism, which hinder the positive cultural exchange between the West and the East as well as go ill with the mutual development of multi-culture.

As for post-colonialist translation theories, there are some limitations. First of all, a fully structured system of translation theories in this field is yet to build. They've highlighted the Oriental resistance against the Western cultural hegemonies from the post-colonialism perspective and pointed out the power differentials. However, power differentials are developed under multi-faceted causes, not only covering historical factors but also closely related to economic, political and cultural tradition elements. Post-colonialist translation theories fail to provide a comprehensive and systematic elaboration of these causes. In the next place, post-colonialist translation theories are not widely applicable in the research practices. They call for changes on the suppressed and silenced position of the Eastern cultures, expecting to underscore the cultural characteristics and reshape the cultural identity of the Oriental world. But to be realistic, resisting the influences of the Western colonial culture is not as necessary as is supposed. Lastly, overemphasis on power differentials may easily give rise to the public hostility of the third-world countries against the Western culture, which does no good to the friendly communication and common development of the Western and Eastern cultures and hence deviates from the original intention of Post-colonialist Translation Theories [6].

\section{SUMMARY}

Post-colonialist translation studies adopt the postcolonialism perspective to examine the translation practices under different historical conditions, uphold the power differentials between cultures, emphasize unearthing from translated texts the power struggles and operations between two cultures, and intend to promote the understanding towards translation practices by the description of the inequality and asymmetry among different nations, cultures, races and languages. Post-colonialist translation studies provide a new perspective for translation researchers. They have reminded us to analyze and criticize translation works from the postcolonialism point of view, and contributed to the extrication of dominated cultures from the ideology of dominant cultures. In the meanwhile, the limitations of such theories should be recognized for the avoidance of blind alienation and ethnocentrism. The theories reveal that, in translation, disadvantageous cultures are subject to the attacks from advantageous cultures due to the relation of cultural powers between societies and nations, and call on the vulnerable cultural groups to join in the collective criticism upon postcolonialism. Extreme comprehension of post-colonialist translation theories should be avoided. We must absorb the essence of the Western culture, initiate dialogues with them, and in the meanwhile constantly maintain the spirit of exploration. However, post-colonialist translation theories form a highly complex and paradoxical system that features both a great number of reasonable insights and some limitations. We still need to chew on and ponder over the approach to fully understand and overcome these limitations, so that the translation studies and practices can be better guided. Although post-colonialism theories carry deficiencies, it is generally known that no theory is perfect. Each theory has a more applicable aspect. Therefore, post-colonialism theories should be utilized in an appropriate and reasonable way. The unique post-colonialism perspective will continue to provide valuable supplements for the theoretical researches and practical activities in the area of translation.

\section{REFERENCES}

[1] J. Y. Zhang, Post-colonial Theory and Cultural Criticism, Beijing: Peking University Press, 1999, pp. 4-5.

[2] D. Robinson, Translation and Empire. Manchester, UK: St Jerome, 1997, pp.13-14,115.

[3] V. Lawrence, Translator's Invisibility: A History of Translation, Shanghai: Shanghai Foreign Languages Press, 2004, p. 20.

[4] L. Venuti, The Translator's Invisibility, Shanghai: Shanghai Foreign Language Education Press, 2004, p.166.

[5] Y. C. Wang, China Mirror: Cultural Studies in the 1990s, Beijing: Central Compilation and Translation Bureau Press, 2001, p.187.

[6] N. Qin, X. T. Fan, An General Survey of Post-colonial Translation Studies, Journal of Zhengzhou Institute of Aeronautical Industry Management: Social Science Edition, Vol. 24(2005)No.5, pp. 67-69. 